\title{
Vignettes
}

\section{Keeping It Real: Teach ACRL Information Literacy Frames with FRED}

\author{
Charissa Jefferson, Diego Mendez-Carbajo, and \\ Katrina Stierholz \\ California State University-Northridge/Illinois Wesleyan University/ \\ Federal Reserve Bank of St. Louis, dmendez@iwu.edu
}

\section{doi: $10.18833 /$ spur $/ 2 / 4 / 3$}

Federal Reserve Economic Data (FRED, https://fred. stlouisfed.org/) is the largest aggregator of economic statistics in the United States. The FRED portal-managed by the Economic Research Division of the Federal Reserve Bank of St. Louis - allows for immediate access to 566,000 (and growing) data series from 87 US and international sources. Examples of how to leverage this rich database for short, course-based research projects have been contributed to the scholarly literature in economic education by multiple authors. Several of these projects are available through the open-access portal Starting Point: Teaching and Learning Economics (https:// serc.carleton.edu/econ/fred). By combining data-search and data-visualization tasks, these projects aim to capitalize on the pedagogical strategy known as inquiry-based, context-rich problems.

However, the enterprise of undergraduate research in economics needs a solid foundation on data and information literacy. To build these skills, instructors can use the free lesson plan "Keeping It Real: Teach ACRL Information Literacy Frames with FRED Data" (https://www.stlouis fed.org/education/keeping-it-real). This peer-reviewed and classroom-tested pedagogical resource is ideally suited for blended teaching environments. It contains both a selfpaced online module and a step-by-step guide for face-toface instruction. The online module "FRED Interactive: Information Literacy" is accessible at econlowdown.org and guides students through data search, data transformation, and visualization tasks. Because the module contains a pretest (a proxy for pre-existing knowledge) and a posttest, instructors can assess - ahead of the actual class time - the amount of value-added learning accrued by the students. The face-to-face instruction builds on the datarelated skills developed through the online module: developing new data visualizations, interpreting information contained in graphs, acknowledging the sources of data, and evaluating the sources of data. Discussion questions guide the student work throughout the lesson. Detailed descriptions of in-class and out-of-class assessment activities also are included.

\section{Development of Local GeoStories: Using Data to Improve Community Health and Enhance Student Learning about the Social Determinants of Health}

\author{
Rebecca Smullin Dawson \\ Allegheny College,rdawson@allegheny.edu
}

doi: $10.18833 /$ spur/2/4/5

The Community Mapping and Analytics Project (MAP) at Allegheny College aims to collect, combine, analyze, and display data from myriad sources, including the US Census, US Department of Transportation, and the Pennsylvania Department of Health, as well as local police departments, 911 call centers, human services agencies, and the community hospital. With this data, the interdisciplinary research team-composed of community organizers, student researchers, a GIS specialist, and an epidemiologist - is creating a single data repository that can be used to answer questions related to community health. MAP is a research and public policy collaboration among academic researchers, including undergraduate researchers, health services providers, and community leaders. The ethical principles of community-based participatory research guide the project.

Now in its third year, MAP provides real-world, applied opportunities for undergraduate researchers through class projects, fourth-year theses, and internships to collect data from national and local databases, merge datasets, conduct analyses, and visualize data (using GIS software) so that the social determinants of health such as poverty, lack of access to health-care facilities, and unemployment, as well as health injustices and challenges facing the community, can be understood.

The result of MAP is the creation of several GeoStories, which incorporate interactive maps, data analyses, and narratives to communicate health needs/challenges within the community. GeoStories, on topics such as the opioid epidemic and domestic violence developed by undergraduate researchers, have been presented to multiple audiences throughout the county and at public health conferences.

Creating a GeoStory requires the researchers to locate, merge, and analyze data from various sources, including large governmental datasets and local agencies/organizations such as the county morgue and courthouse. Combining data requires student researchers to identify commonalities within and among datasets so they can merge data into a single format for spatial analysis. Using GIS 